\title{
Colorectal cancer prognosis depends on T-cell infiltration and molecular characteristics of the tumor
}

\author{
Anna M Dahlin ${ }^{1}$, Maria L Henriksson ${ }^{1}$, Bethany Van Guelpen ${ }^{1}$, Roger Stenling ${ }^{1}$, \\ Åke Öberg ${ }^{2}$, Jörgen Rutegård ${ }^{2}$ and Richard Palmqvist ${ }^{1}$ \\ ${ }^{1}$ Department of Medical Biosciences, Pathology, Umea University, Umea, Sweden and \\ ${ }^{2}$ Department of Surgical and Perioperative Sciences, Surgery, Umea University, Umea, Sweden
}

\begin{abstract}
The aim of this study was to relate the density of tumor infiltrating $T$ cells to cancer-specific survival in colorectal cancer, taking into consideration the $\mathrm{CpG}$ island methylator phenotype (CIMP) and microsatellite instability (MSI) screening status. The T-cell marker CD3 was stained by immunohistochemistry in $\mathbf{4 8 4}$ archival tumor tissue samples. T-cell density was semiquantitatively estimated and scored 1-4 in the tumor front and center ( $T$ cells in stroma), and intraepithelially ( $T$ cells infiltrating tumor cell nests). Total CD3 score was calculated as the sum of the three CD3 scores (range 3-12). MSI screening status was assessed by immunohistochemistry. CIMP status was determined by quantitative real-time PCR (MethyLight) using an eightgene panel. We found that patients whose tumors were highly infiltrated by T cells (total CD3 score $\geq 7$ ) had longer survival compared with patients with poorly infiltrated tumors (total CD3 score $\leq 4$ ). This finding was statistically significant in multivariate analyses (multivariate hazard ratio, 0.57 ; $95 \%$ confidence interval, $0.31-$ 1.00). Importantly, the finding was consistent in rectal cancer patients treated with preoperative radiotherapy. Although microsatellite unstable tumor patients are generally considered to have better prognosis, we found no difference in survival between microsatellite unstable and microsatellite stable (MSS) colorectal cancer patients with similar total CD3 scores. Patients with MSS tumors highly infiltrated by $T$ cells had better prognosis compared with intermediately or poorly infiltrated microsatellite unstable tumors (log rank $P=0.013)$. Regarding CIMP status, CIMP-low was associated with particularly poor prognosis in patients with poorly infiltrated tumors (multivariate hazard ratio for CIMP-low versus CIMP-negative, 3.07; 95\% confidence interval, 1.53-6.15). However, some subset analyses suffered from low power and are in need of confirmation by independent studies. In conclusion, patients whose tumors are highly infiltrated by $T$ cells have a beneficial prognosis, regardless of MSI, whereas the role of CIMP status in this context is less clear.

Modern Pathology (2011) 24, 671-682; doi:10.1038/modpathol.2010.234; published online 14 January 2011
\end{abstract}

Keywords: colorectal neoplasms; host immune response; immunotherapy; microsatellite instability (MSI); prognosis; T-lymphocytes; the $\mathrm{CpG}$ island methylator phenotype (CIMP)

Colorectal cancer is one of the most common malignancies in the western world, and has a lethal outcome in nearly $40 \%$ of all diagnosed cases. The current staging system used for therapeutic decision making and prediction of patient survival accurately identifies patients with exceptionally good prognosis (stage I), as well as patients with very poor

Correspondence: AM Dahlin, MS, Department of Medical Biosciences, Pathology, Building $6 \mathrm{M}$, 2nd Floor, Umeå University, SE-90185 Umeå, Sweden.

E-mail: anna.dahlin@medbio.umu.se

Received 20 August 2010; revised 2 November 2010; accepted 2

November 2010; published online 14 January 2011 prognosis (stage IV). However, additional factors are needed in the large subgroup of patients with stage II or III disease, for whom the prognosis and potential benefit of adjuvant chemotherapy are less certain.

Microsatellite instability (MSI) characterizes 10$15 \%$ of sporadic colorectal cancer, and has been related to a better patient prognosis compared with microsatellite stable (MSS) colorectal cancer. ${ }^{1,2}$ MSI in sporadic colorectal cancer is frequently caused by promoter hypermethylation of the mismatch repair gene $M L H 1^{3}$ and is highly associated with the CpG island methylator phenotype (CIMP). ${ }^{4}$ CIMP-high, or CIMP1, is characterized by hypermethylation in several genes that are unmethylated in normal 
colorectal tissue and in CIMP-negative colorectal cancer. $^{5}$ CIMP classification has recently been expanded to define a group of tumors with hypermethylation of an intermediate number of genes, called CIMP-low or CIMP2. ${ }^{6-8}$ The importance of CIMP status in predicting colorectal cancer patient survival has been investigated in a number of recent studies. Along with others, we have reported a worse prognosis in colorectal cancer patients with CIMP-low or CIMP-high, compared with CIMPnegative tumors, particularly in combination with MSS. ${ }^{4,9-12}$ However, results from other large studies have not been entirely consistent,${ }^{13-18}$ and consensus has thus not been reached. One factor contributing to the discrepancy of results in the many studies is the lack of information regarding $B R A F$ mutation, which has shown to be a major confounding factor in studies of CIMP status and colorectal cancer patient survival. ${ }^{12,14,15,17}$ Some studies have focused on the clinical importance of the host response in terms of tumor infiltrating immune cells. Presence of peri- and intratumoral inflammatory cells has consistently been associated with a better prognosis in colorectal cancer. ${ }^{19-33}$ Many of these reports have been based on routine hematoxylin and eosin stained tissue sections, but an increasing number of studies have used immunohistochemical markers such as the pan T-cell marker CD3. CD3 is a cell surface protein associated with the T-cell receptor. ${ }^{34}$

CIMP-high and MSI tumors are frequently infiltrated by a large number of $\mathrm{T}$ cells. ${ }^{4,35-38}$ However, few large studies of tumor infiltrating $\mathrm{T}$ cells and colorectal cancer patient survival have taken into account the potentially confounding effect of MSI screening status, ${ }^{30,32,39-42}$ and only one other research group has considered CIMP. ${ }^{32,42}$ Furthermore, T-cell infiltration can be assessed in various locations within the tumor, such as the tumor front, tumor center, and the intraepithelial compartment, but few studies have evaluated these separately. ${ }^{32,33,37,42-47}$ Although a beneficial effect on survival has generally been observed with higher degrees of infiltrating $\mathrm{T}$ cells, the prognostic value has varied in reports depending on the T-cell marker used, the compartment evaluated, and the confounders considered.

The aim of this study was to relate the extent and location of tumor infiltrating $\mathrm{T}$ cells to colorectal cancer patient prognosis, and to investigate the potentially confounding effect of MSI screening status and CIMP status.

\section{Patients and methods}

\section{Study Design and Patient Selection}

Colorectal cancer cases included in this study were from the Colorectal Cancer in Umeå Study (CRUMS), which comprises patients with primary colorectal cancer who underwent curative or palliative tumor resective surgery between 1995 and 2003 at Umeå University Hospital, Sweden. The sample collection had a consecutive intent, and exclusion criteria included insufficient or unavailable tumor tissue sample and insufficient clinical information. After further exclusion of 9 cases in which CD3 staining was unsuccessful, 484 cases (297 colon cancer, 182 rectal cancer, and 5 missing values), were available for this study. Adjuvant chemotherapy was administered to $68(14 \%)$ patients. Preoperative radiotherapy was administered to 110 $(60 \%)$ rectal cancer patients, of whom 83 received $5 \times 5 \mathrm{~Gy}$, and 27 received $25 \times 2 \mathrm{~Gy}$.

Verification of diagnoses and classification of tumor characteristics were performed by one pathologist. Information on patient age, sex, and tumor site were extracted from patient records, and vital status and cancer-specific survival were obtained from the Swedish population registry and patient records, respectively. Patients were followed up until spring 2005. The median follow-up time for cases that were still alive at the end of follow-up was 50 months. The tumors have previously been characterized for $B R A F$ V600E mutation status by the Taqman allelic discrimination assay. ${ }^{48,49}$

The handling of tissue samples and patient data in this study has been approved by the ethical committee, Umeå University, Umeå, Sweden.

\section{Immunohistochemistry and MSI Screening Status}

Colorectal cancer specimens obtained after primary tumor resection were formalin fixed and paraffin embedded according to routine protocols. For immunohistochemical stainings, $4 \mu \mathrm{m}$ sections were deparaffinized and rehydrated, and antigen retrieval treatment was executed by heating in a microwave oven in citrate pH 6.0 (for CD3) or EDTA pH 8.0 (for MLH1, MSH2, MSH6, and PMS2). Primary polyclonal CD3 (dilution 1:50; Dako, Glostrup, Denmark) or monoclonal MLH1 (clone G168-15; 1:50; BD Biosciences, Pharmingen, San Diego, CA, USA), MSH6 (clone 44; 1:50; BD Biosciences, Pharmingen), PMS2 (clone A16-4; 1:25; BD Biosciences, Pharmingen), or MSH2 (clone FE11; 1:50; Oncogene/VWR, West Chester, PA, USA) antibodies were used. Subsequent steps, including use of 2,3diaminobenzidine chromogen (iVIEW DAB Detection Kit, Ventana, Illkirch CEDEX, France) for visualization, was carried out in a semiautomatic staining machine (Ventana ES; Ventana).

Non-malignant lymph nodes were used as a positive control for CD3 staining, and non-malignant stromal cells were used as internal positive controls for MLH1, MSH2, MSH6, and PMS2. Cases lacking positivity in control cells were considered uninformative. Tissue samples with tumor cells lacking nuclear staining for MLH1, MSH2, MSH6, or PMS2 were considered to have a positive MSI screening status, which is hereafter referred to as MSI. Negative MSI screening status is hereafter 
referred to as MSS. MSI screening status could not be determined for 14 patients.

\section{Immunohistochemical Evaluation of T-Cell Infiltration}

T-cell infiltration of tumors was assessed by semiquantitative estimation of the density of CD3-positive $(\mathrm{CD} 3+)$ cells, and was scored as 1 , no, or sporadic CD3 + cells; 2, moderate numbers of CD3 + cells; 3 , abundant occurrence of CD3 + cells; and 4, highly abundant occurrence of CD3 + cells (Figure 1). In each tumor, the density of T-cell infiltration was examined in, and a separate CD3 score was assigned for, the tumor front (CD3 + cells localized in stroma adjacent to the invasive tumor margin), the tumor center (CD3 + cells localized in the stroma within the tumor mass), and the intraepithelial compartment $\left(\mathrm{CD} 3+\right.$ cells localized within tumor cell nests). ${ }^{44}$ Areas of necrosis were avoided. In cases of heterogeneity, the CD3 score for the tumor front was estimated in the area of deepest invasion. For assessment of tumor center and intraepithelial compartment, at least three random fields were viewed, and in cases of heterogeneity, the score that was most representative for the entire section was assigned. All sections were examined twice by the same observer, and in cases of discrepant scoring, a third estimation was made and set as the final score. Staining was successful for 484 cases, but because of technical limitations, for example, a lack of identifiable tumor invasive front in the investigated tissue sections, a CD3 score for the tumor front, center, and intraepithelial compartment could not be determined in 23, 1 , and 6 cases, respectively (total $n=29$ ).

Similar to Ogino et $a,^{32}$ a total CD3 score was calculated as the sum of the CD3 scores in the tumor front, center, and intraepithelial compartment, generating a total CD3 score ranging from 3 to 12 . On the basis of the total CD3 score, patients were divided into three equally sized groups with either low (3-4), intermediate (5-6), or high (7-12) total CD3 score.

\section{Methylation Analysis}

The MethyLight method (quantitative real-time PCR) and primer and probe sequences used to determine
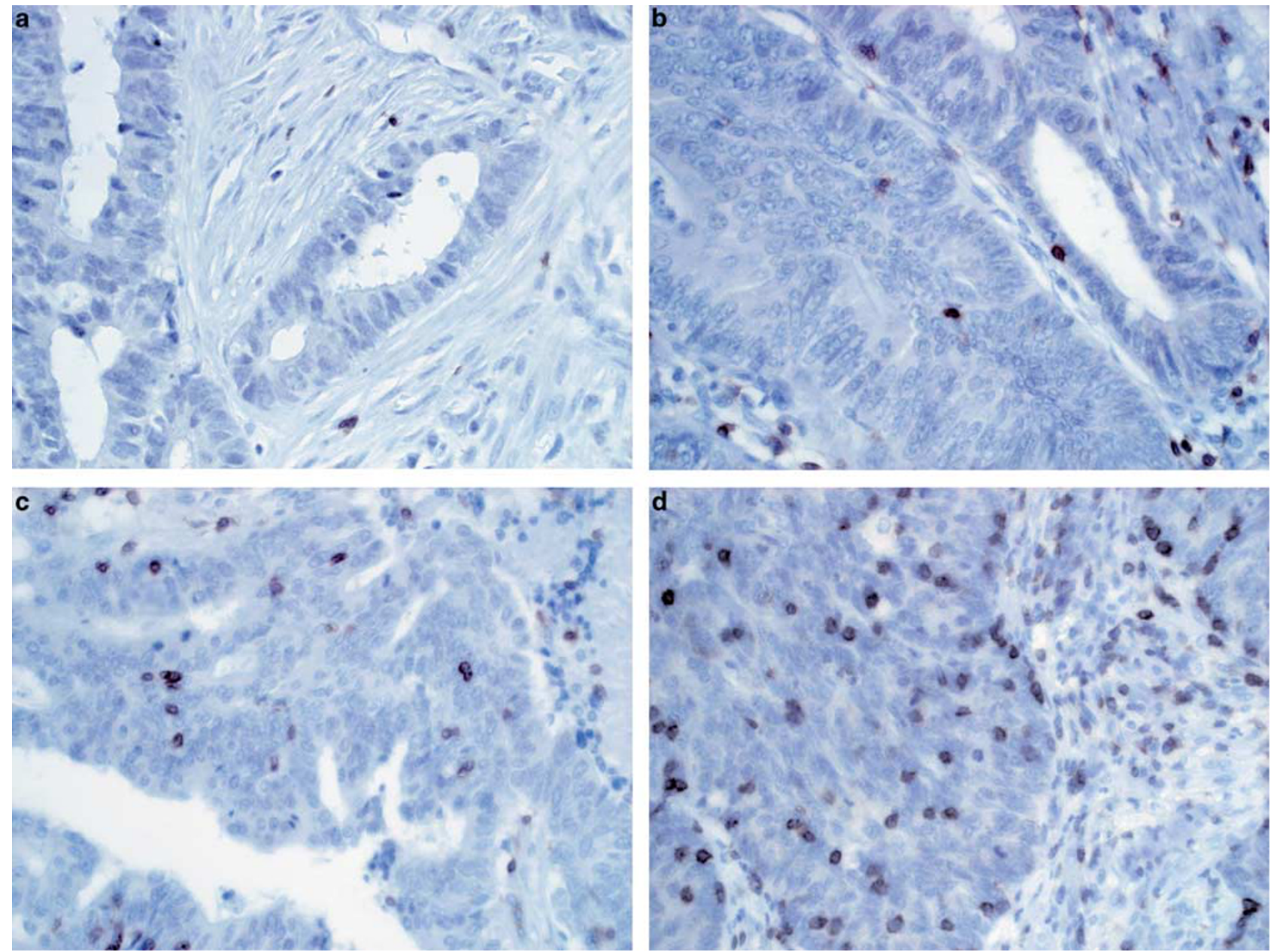

Figure 1 Representative examples of tumors with intraepithelial CD3 score (a) 1, no, or sporadic CD3 + cells; (b) 2, moderate numbers of CD3 + cells; (c) 3, abundant occurrence of CD3 + cells; and (d) 4, highly abundant occurrence of CD3 + cells 
tumor CIMP status in this study have been described in detail elsewhere. ${ }^{49,50}$ DNA extracted from formalin-fixed, paraffin-embedded colorectal cancer tissue was bisulfite treated and purified using the EZ DNA methylation kit (Zymo Research, Orange, CA, USA). For all bisulfite-treated DNA samples, one reaction was run for each of the eight genes included in the CIMP panel (CDKN2A, MLH1, CACNA1G, NEUROG1, RUNX3, SOCS1, IGF2, and CRABP1). Although there is no consensus panel for the determination of CIMP status, this eight-gene panel has been thoroughly validated ${ }^{50,51}$ and the included methylation marker genes have been used in several large CIMP studies..$^{15-17,50}$ In order to account for the amount of input bisulfite-treated DNA, one reaction amplifying the repetitive $A L U$ sequence was also run for each DNA sample. M.SssI-treated DNA (presumably fully methylated) served as a methylated reference in control reactions to account for the efficiency of PCR amplification, and for use in standard curve reactions. The percentage of methylated reference (PMR) value was calculated for each gene by the following equation: (quantity of the genespecific reaction of the sample/quantity of the $A L U$ reaction of the sample)/(mean quantity of the genespecific reaction for the methylated reference sample/mean quantity of the $A L U$ reaction for the methylated reference sample). ${ }^{50}$ Samples were considered positive for methylation when an exponential amplification curve was present and generated a PMR $>100^{50}$ CIMP status was successfully determined for all patients.

\section{Statistics}

Correlations between different CD3 scores were determined by non-parametric Spearman's rho, and clinicopathological characteristics of subgroups were compared using non-parametric KruskalWallis tests for continuous variables and $\chi^{2}$ tests for categorical variables. Cancer-specific events were defined as death with known disseminated or recurrent disease, and cases were censored at the end of follow-up or at time of death by other causes. For survival analyses, Kaplan-Meier plots were employed, and differences in survival between groups were tested by log rank tests. In order to take into consideration other clinicopathological factors, multivariate Cox proportional hazard models were employed. On the basis of our previous prognostic study, ${ }^{12}$ the final multivariate model included sex, age at diagnosis, tumor site, tumor stage, and adjuvant chemotherapy. Patients who died with postoperative complications within 1 month after surgery $(n=19)$, and patients for whom complete follow-up data were lacking $(n=19)$, were excluded from the survival analyses. Missing values for MSI screening status were treated as a separate category in multivariate survival analyses $(n=10)$. All statistical tests were conducted using PASW Statistics 18 (SPSS, Chicago, IL, USA). Findings were considered statistically significant if $P<0.05$.

\section{Results}

\section{CD3 Scores}

The distributions of CD3 scores were similar in the tumor front, center, and intraepithelial compartment (Table 1). The CD3 scores in all compartments, and the total CD3 score (the sum of the three measures), were highly correlated (all Spearman correlation coefficients $>0.567$, and all $P<0.0001$ ).

Table 1 Distribution of CD3 scores in the tumor front, center, and the intraepithelial compartment, in all cases and in subgroups based on MSI screening status and CIMP status

\begin{tabular}{|c|c|c|c|c|c|c|c|c|c|}
\hline \multirow[t]{3}{*}{ Tumor compartment } & \multirow{2}{*}{\multicolumn{2}{|c|}{$\begin{array}{c}\text { Front } \\
\text { CD3 score }\end{array}$}} & \multirow[t]{3}{*}{$\mathrm{P}^{\mathrm{a}}$} & \multirow{2}{*}{\multicolumn{2}{|c|}{$\begin{array}{c}\text { Center } \\
\text { CD3 score }\end{array}$}} & \multirow[t]{3}{*}{$\mathrm{P}^{\mathrm{a}}$} & \multirow{2}{*}{\multicolumn{2}{|c|}{$\begin{array}{c}\text { Intraepithelially } \\
\text { CD3 score }\end{array}$}} & \multirow[t]{3}{*}{$\mathrm{P}^{\mathrm{a}}$} \\
\hline & & & & & & & & & \\
\hline & $1-2$ & $3-4$ & & $1-2$ & $3-4$ & & $1-2$ & $3-4$ & \\
\hline All cases & 344 & 117 & & 386 & 97 & & 377 & 101 & \\
\hline $\begin{array}{l}\text { MSI screening status, n (\%) } \\
\text { MSI } \\
\text { MSS }\end{array}$ & $\begin{array}{r}42(12) \\
294(88)\end{array}$ & $\begin{array}{l}27(24) \\
86(76)\end{array}$ & 0.004 & $\begin{array}{r}52(14) \\
323(86)\end{array}$ & $\begin{array}{l}20(21) \\
74(79)\end{array}$ & 0.075 & $\begin{array}{r}45(12) \\
320(88)\end{array}$ & $\begin{array}{l}27(27) \\
72(73)\end{array}$ & 0.00027 \\
\hline $\begin{array}{l}\text { CIMP status, n (\%) } \\
\text { CIMP-negative } \\
\text { CIMP-low }^{\mathrm{b}} \\
\text { CIMP-high }^{\mathrm{b}}\end{array}$ & $\begin{array}{r}173(50) \\
134(39) \\
37(11)\end{array}$ & $\begin{array}{l}55(47) \\
43(37) \\
19(16)\end{array}$ & 0.292 & $\begin{array}{r}190(49) \\
155(40) \\
41(11)\end{array}$ & $\begin{array}{l}53(55) \\
27(28) \\
17(18)\end{array}$ & 0.036 & $\begin{array}{c}194(51) \\
148(39) \\
35(9)\end{array}$ & $\begin{array}{l}46(46) \\
32(32) \\
23(23)\end{array}$ & 0.001 \\
\hline
\end{tabular}




\section{Clinical Characteristics According to Total CD3 Score}

In order to compare tumors with low, intermediate, and high densities of infiltrating $\mathrm{T}$ cells, tumors were divided into three subgroups comprising total CD3 scores 3-4, 5-6, and 7-12. A similar approach was recently used in a study by Ogino et al. ${ }^{32} \mathrm{~A}$ high total CD3 score was associated with lower stage and lower grade (Table 2). Rectal cancer patients who received preoperative radiotherapy more often had a low total CD3 score (Table 2). On the basis of this and previous findings, ${ }^{52}$ preoperatively radiated tumors were considered separately in survival analyses, and were excluded from the results below unless otherwise stated.

\section{Cancer-Specific Survival and CD3 Scores}

A high total CD3 score, as well as high CD3 scores in the tumor front, center, and intraepithelial compartment, were associated with a longer cancer-specific survival (Figure 2 and Supplementary Figure S1). The longer cancer-specific survival in patients with a high total CD3 score was statistically significant in multivariate analyses adjusted for sex, age, tumor site, tumor stage, and adjuvant chemotherapy (multivariate hazard ratio (HR), 0.57; 95\% confidence interval (CI), 0.31-1.00; Table 3). HRs for high CD3 scores in the tumor front, center, and intraepithelial compartment were similar to those of a high total CD3 score (data not shown).

The longer cancer-specific survival in patients with a high total CD3 score was consistent in analyses stratified by stage. Although these analyses suffered from low power, statistical significance was reached for stage II, in which multivariate HR for high versus low total CD3 score was 0.25 (95\% CI, 0.08-0.75; Supplementary Figure S2).

\section{Cancer-Specific Survival by Combined Total CD3 Score and MSI Screening Status}

Cancer-specific survival was longer in MSI compared with MSS tumor patients, although the difference was not statistically significant (5-year cancer-specific survival 72 and $57 \%$, respectively; $\log$ rank $P=0.078$; Table 4). MSI was associated with a high total CD3 score and high CD3 scores in the tumor front and intraepithelially (Tables 1 and 2). However, addition of MSI screening status to the multivariate model in Table 3 did not affect the HRs for total CD3 score. In analyses combining total CD3 score and MSI screening status, 5-year cancerspecific survival was highest in patients with a high total CD3 score and either MSI or MSS (87 and 83\%, respectively; Table 4; Figures 3a-d), and lowest in cases with low total CD3 score and either MSI or MSS (51 and 39\%, respectively; Table 4; Figures 3a-d). MSI screening status was not an independent predictor of cancer-specific survival when included in the same multivariate model as total CD3 score (data not shown). Patients with MSS tumors with a high total CD3 score had longer cancer-specific survival compared with MSI tumors with an intermediate or low total CD3 score (log rank $P=0.013$; Figures 3a-d). When comparing cancer-specific survival in patients within the same total CD3 score subgroup, no statistically significant differences were found between MSI and MSS tumor patients (Table 4; Figures 3a-d).

\section{Cancer-Specific Survival by Combined Total CD3 Score and CIMP Status}

As previously reported for patients in CRUMS, ${ }^{12}$ CIMP-low patients had a poorer prognosis compared with CIMP-negative, which was of borderline statistical significance in multivariate analyses (5-year cancer-specific survival 52 and $63 \%$, respectively; multivariate HR for CIMP-low, 1.47; 95\% CI, 0.982.20; Table 4). Cancer-specific survival was similar in CIMP-high and CIMP-negative tumor patients (Table 4). CIMP status was associated with CD3 scores in the tumor center and intraepithelial compartment $(P=0.036$ and 0.001 , respectively; Table 1), but not with CD3 score in the tumor front, or with total CD3 score $(P>0.05$; Tables 1 and 2$)$. Addition of CIMP status to the multivariate model in Table 3 had no effect on the HRs for total CD3 score. Total CD3 score and CIMP status were both independent predictors of cancer-specific survival when included in the same multivariate model (data not shown).

In patients with a low total CD3 score, CIMP-low was associated with a reduced cancer-specific survival compared with CIMP-negative (Figure 3e). This finding was statistically significant in multivariate analyses (multivariate $\mathrm{HR}$ for CIMP-low, 3.07; 95\% CI, 1.53-6.15; Table 4). In contrast, no statistically significant differences in cancer-specific survival were found between CIMP-low and CIMPnegative patients with intermediate or high total CD3 score (Figures 3f-g; Table 4). No statistically significant differences in cancer-specific survival were found between CIMP-high and CIMP-negative patients, regardless of total CD3 score (Figures $3 \mathrm{e}-\mathrm{h}$; Table 4).

\section{Total CD3 Score and Cancer-Specific Survival in Preoperatively Radiated Rectal Cancers}

A high total CD3 score was less common in rectal cancer tissue that had been preoperatively radiated with $5 \times 5$ Gy compared with non-preoperatively radiated rectal cancers (14 and $40 \%$, respectively; $P=0.002$ ). In both groups, a high total CD3 score was associated with a longer cancer-specific survival (for high versus low total CD3 score, log rank $P=0.028$ and 0.017 , respectively; Supplementary Figure S3). 
Table 2 Clinical and molecular characteristics of colorectal cancer cases according to total CD3 score

\begin{tabular}{|c|c|c|c|c|c|}
\hline & \multicolumn{5}{|c|}{ Total CD3 score } \\
\hline & Total $^{\mathrm{a}}$ & $3-4$ & $5-6$ & $7-12$ & $\mathrm{P}^{\mathrm{b}}$ \\
\hline Frequency, $n(\%)$ & 455 & $147(32)$ & $163(36)$ & $145(32)$ & \\
\hline Age at diagnosis, median years (range) & $71(26-93)$ & $70(37-91)$ & $71(30-89)$ & $73(26-93)$ & 0.067 \\
\hline Sex, n $(\%)$ & & & & & 0.914 \\
\hline Men & $248(55)$ & $79(54)$ & $91(56)$ & $78(54)$ & \\
\hline Women & $207(45)$ & $68(46)$ & $72(44)$ & $67(46)$ & \\
\hline Tumor site, $\mathrm{n}(\%)^{\mathrm{a}}$ & & & & & 0.335 \\
\hline Right-sided colon & $140(31)$ & $38(26)$ & $48(29)$ & $54(38)$ & \\
\hline Left-sided colon & $141(31)$ & $48(33)$ & $51(31)$ & $42(29)$ & \\
\hline Rectum & $170(38)$ & $58(40)$ & $64(39)$ & $48(33)$ & \\
\hline Stage, $\mathrm{n}(\%)^{\mathrm{a}}$ & & & & & $<0.0001$ \\
\hline I & 74 (17) & $10(7)$ & $24(15)$ & $40(28)$ & \\
\hline II & $178(40)$ & $40(28)$ & $69(43)$ & 69 (49) & \\
\hline III & $92(21)$ & $38(27)$ & $34(21)$ & $20(14)$ & \\
\hline IV & $100(23)$ & $54(38)$ & $33(21)$ & $13(9)$ & \\
\hline Tumor grade, $\mathrm{n}(\%)^{\mathrm{a}}$ & & & & & 0.002 \\
\hline Well/well-to-moderately differentiated & $218(49)$ & $54(38)$ & $83(51)$ & $81(58)$ & \\
\hline Moderately-to-poorly/poorly differentiated & $229(51)$ & $90(62)$ & $80(49)$ & $59(42)$ & \\
\hline Histology type, n (\%) ${ }^{\mathrm{a}}$ & & & & & 0.328 \\
\hline Non-mucinous & $384(86)$ & $119(83)$ & $138(86)$ & $127(89)$ & \\
\hline Mucinous & $64(14)$ & $25(17)$ & $23(14)$ & $16(11)$ & \\
\hline Adjuvant chemotherapy, n (\%) ${ }^{\mathrm{a}}$ & & & & & 0.178 \\
\hline No & $381(86)$ & $117(82)$ & $140(89)$ & $124(87)$ & \\
\hline Yes & $62(14)$ & $26(18)$ & $17(11)$ & $19(13)$ & \\
\hline Preoperative radiation, $\mathrm{n}(\%)^{\mathrm{c}}$ & & & & & 0.016 \\
\hline No & $68(40)$ & $17(29)$ & $24(38)$ & $27(56)$ & \\
\hline Yes & $102(60)$ & $41(71)$ & $40(62)$ & $21(44)$ & \\
\hline MSI screening status, $\mathrm{n}(\%)^{\mathrm{a}}$ & & & & & 0.003 \\
\hline MSI & $69(16)$ & $12(8)$ & $25(16)$ & $32(23)$ & \\
\hline MSS & $374(84)$ & $133(92)$ & $133(84)$ & $108(77)$ & \\
\hline CIMP status, n (\%) & & & & & 0.104 \\
\hline CIMP-negative ${ }^{\mathrm{d}}$ & $225(49)$ & $75(51)$ & $81(50)$ & $69(48)$ & \\
\hline CIMP-low ${ }^{\mathrm{d}}$ & $174(38)$ & $61(41)$ & $63(39)$ & $50(34)$ & \\
\hline CIMP-high $^{\mathrm{d}}$ & $56(12)$ & $11(7)$ & $19(12)$ & $26(18)$ & \\
\hline BRAF V600E, n $(\%)^{\mathrm{a}}$ & & & & & 0.225 \\
\hline Wild type & $386(86)$ & $124(86)$ & $144(89)$ & $118(82)$ & \\
\hline Mutated & $65(14)$ & $21(14)$ & $18(11)$ & $26(18)$ & \\
\hline
\end{tabular}

Abbreviations: CIMP, CpG island methylator phenotype, according to an eight-gene panel; MSI, microsatellite instability; MSS, microsatellite stable.

${ }^{\mathrm{a}}$ Total CD3 score could be calculated in 455 of the 484 colorectal cancer tumors included in this study. Among these, missing cases were present in the following variables: tumor site, 4; stage, 11; grade, 8; histology type, 7; adjuvant chemotherapy, 12; MSI screening status, 12 ; $B R A F$ mutation status, 4.

${ }^{\mathrm{b}}$ Kruskall-Wallis test for continuous variables, $\chi^{2}$ test for categorical variables.

${ }^{\mathrm{C}}$ Preoperative radiation therapy in rectal cancer cases only.

d CIMP-negative, 0 genes hypermethylated; CIMP-low, 1-5 genes hypermethylated; CIMP-high, 6-8 genes hypermethylated.

A high total CD3 score was found in $38 \%$ of rectal cancers that were preoperatively radiated with $25 \times 2$ Gy, which did not differ significantly from non-preoperatively radiated rectal cancers $(P=$ 0.837). In survival analysis of this small subgroup of patients ( $n$ with total CD3 score and complete follow-up data $=21$ ), total CD3 score was not statistically significantly related to cancer-specific survival (data not shown).

\section{Discussion}

In this study, colorectal cancer patients whose tumors were densely infiltrated by $\mathrm{T}$ cells had a 
longer cancer-specific survival compared with patients whose tumors were poorly infiltrated. This finding was independent of MSI screening status and CIMP status. Notably, no differences in cancerspecific survival were found between MSI and MSS patients with similar degrees of T-cell infiltration. Thus, the longer survival often reported for $\mathrm{MSI}^{1,2}$ is, at least partly, dependent on T-cell infiltration. Patients with poorly infiltrated CIMP-low tumors had a particularly poor prognosis. T-cell infiltration and CIMP status, but not MSI screening status, were independent predictors of patient survival. However, subset analyses of MSI and CIMP subgroups suffered from low power, and confirmation by independent data sets is needed.

The first reports of a better prognosis in patients with colorectal tumors highly infiltrated by immune cells, ${ }^{19-22}$ have later been confirmed in several large studies including multivariate analysis. ${ }^{24-33}$ As in this study, MSI tumors have previously

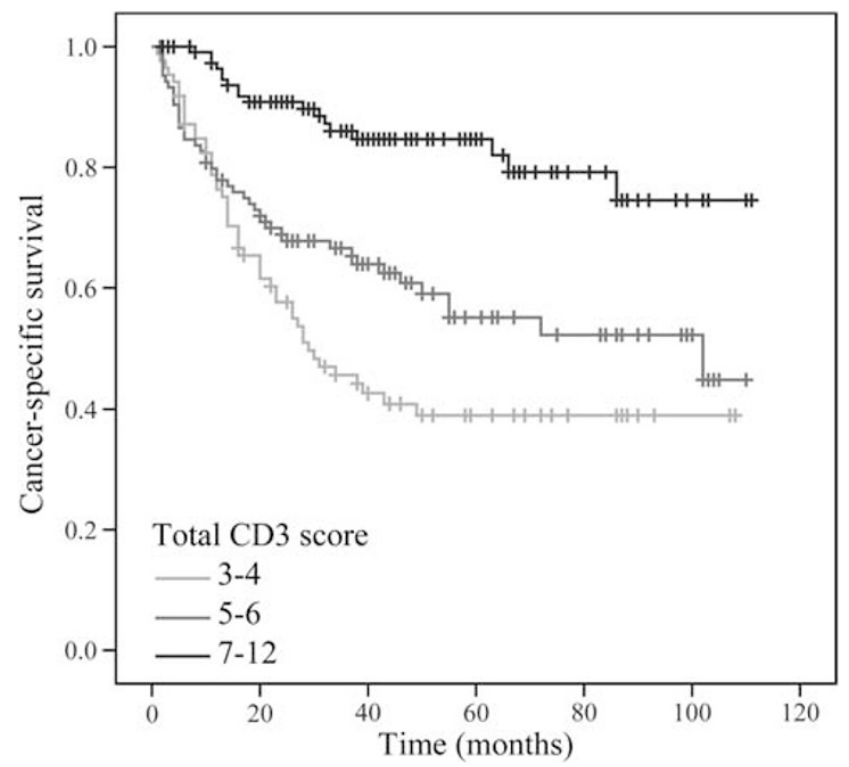

Figure 2 Cancer-specific survival in colorectal cancer patients with low (3-4), intermediate (5-6), and high (7-12) total CD3 score (log rank $P<0.0001)$. been reported to have a higher degree of T-cell infiltration than MSS tumors. ${ }^{35-37}$ Yet the potential confounding effect of MSI screening status on the prognostic importance of T-cell infiltration has been considered in only a minority of reports, of which most, ${ }^{32,36,39-41,46,53,54}$ but not all, ${ }^{30,55}$ found that the better prognosis associated with dense T-cell infiltration was independent of MSI screening status. In this study, a better prognosis was seen in patients with MSS tumors densely infiltrated by $\mathrm{T}$ cells compared with poorly or intermediately infiltrated MSI tumors, whereas MSI screening status was not significantly related to prognosis in subgroups of highly and poorly infiltrated tumors separately. Taken together, these results indicate that the density of $\mathrm{T}$ cells is an independent prognostic factor, perhaps even more important than MSI screening status.

An increasing amount of evidence supports the importance of identifying subgroups of colorectal cancer based on molecular characteristics, and much attention has recently been paid to the CIMP classification. ${ }^{8,56,57}$ In this study, cancer-specific survival was comparatively high in all patients with tumors highly infiltrated by $\mathrm{T}$ cells, regardless of CIMP status. However, in the subgroup of colorectal cancers that were poorly infiltrated by T cells, CIMPlow patients had a poorer prognosis. Only one other research group has considered the potential influence of CIMP status on the relationship between T-cell infiltration and colorectal cancer patient survival. $^{32,42}$ As in this study, a beneficial effect of a dense T-cell infiltration, independent of CIMP status, was reported.

Our findings of a beneficial prognosis in colorectal cancer patients with tumors densely infiltrated by $\mathrm{T}$ cells were consistent in stage-stratified analyses, and were statistically significant in stage II colorectal cancers. A prognostic marker indicating risk of recurrence and cancer-related death is of particular clinical interest in stage II colorectal cancer, since high-risk patients within this subgroup may potentially benefit from adjuvant chemotherapy, which today is not routinely administered. Together with other stage-stratified results, ${ }^{21,24,40,41,47,55,58}$

Table 3 HRs and 95\% CIs for cancer-specific death in colorectal cancer subgroups based on total CD3 score

\begin{tabular}{|c|c|c|c|c|c|}
\hline & $\begin{array}{c}\text { Cases/cancer-specific } \\
\text { deaths (n) }\end{array}$ & Univariate & $\begin{array}{l}\text { Multivariate } H R \\
(95 \% C I)^{\mathrm{a}}\end{array}$ & $\begin{array}{l}\text { Multivariate adjusted } \\
\text { for MSI screening status }\end{array}$ & $\begin{array}{l}\text { Multivariate adjusted } \\
\text { for CIMP status }{ }^{\mathrm{a}, \mathrm{b}}\end{array}$ \\
\hline \multicolumn{6}{|c|}{ Total CD3 score } \\
\hline $3-4$ & $86 / 48$ & 1 & 1 & 1 & 1 \\
\hline $5-6$ & $106 / 43$ & $0.67(0.44-1.01)$ & $1.41(0.89-2.23)$ & $1.43(0.90-2.28)$ & $1.39(0.88-2.21)$ \\
\hline $7-12$ & $116 / 18$ & $0.23(0.12-0.38)$ & $0.57(0.31-1.00)$ & $0.57(0.31-1.02)$ & $0.55(0.30-0.99)$ \\
\hline
\end{tabular}


Table 4 HRs and 95\% CIs for cancer-specific death according to MSI screening status and CIMP status in colorectal cancer patients with low, intermediate, and high total CD3 score

\begin{tabular}{|c|c|c|c|c|}
\hline & \multirow[b]{2}{*}{ All cases } & \multicolumn{3}{|c|}{ Total CD3 score } \\
\hline & & $3-4$ & $5-6$ & $7-12$ \\
\hline \multicolumn{5}{|l|}{ MSI screening status } \\
\hline \multicolumn{5}{|l|}{ MSI } \\
\hline 5-year cancer-specific survival & $72 \%$ & $51 \%$ & $63 \%$ & $87 \%$ \\
\hline Univariate HR & 1 & 1 & 1 & 1 \\
\hline Multivariate $\mathrm{HR}^{\mathrm{a}}$ & 1 & 1 & 1 & 1 \\
\hline \multicolumn{5}{|l|}{ MSS } \\
\hline 5-year cancer-specific survival & $57 \%$ & $39 \%$ & $54 \%$ & $83 \%$ \\
\hline Univariate $\mathrm{HR}$ & $1.64(0.93-2.87)$ & $1.48(0.46-4.78)$ & $1.03(0.45-2.34)$ & $1.91(0.55-6.65)$ \\
\hline Multivariate $\mathrm{HR}^{\mathrm{a}}$ & $1.16(0.64-2.08)$ & $0.78(0.23-2.61)$ & $1.02(0.41-2.58)$ & $2.64(0.62-11.25)$ \\
\hline \multicolumn{5}{|l|}{ CIMP status } \\
\hline \multicolumn{5}{|l|}{ CIMP- $0^{\mathrm{b}}$} \\
\hline 5-year cancer-specific survival & $63 \%$ & $48 \%$ & $60 \%$ & $84 \%$ \\
\hline Univariate $\mathrm{HR}$ & 1 & 1 & 1 & 1 \\
\hline Multivariate $\mathrm{HR}^{\mathrm{a}}$ & 1 & 1 & 1 & 1 \\
\hline \multicolumn{5}{|l|}{ CIMP-low ${ }^{\mathrm{b}}$} \\
\hline 5-year cancer-specific survival & $52 \%$ & $29 \%$ & $51 \%$ & $88 \%$ \\
\hline Univariate HR & $1.46(0.99-2.16)$ & $2.11(1.14-3.89)$ & $1.23(0.64-2.38)$ & $0.77(0.25-2.28)$ \\
\hline Multivariate $\mathrm{HR}^{\mathrm{a}}$ & $1.47(0.98-2.20)$ & $3.07(1.53-6.15)$ & $1.24(0.60-2.55)$ & $0.58(0.17-1.92)$ \\
\hline \multicolumn{5}{|l|}{ CIMP-high $^{\mathrm{b}}$} \\
\hline 5-year cancer-specific survival & $64 \%$ & $50 \%$ & $53 \%$ & $81 \%$ \\
\hline Univariate HR & $1.00(0.57-1.76)$ & $0.99(0.33-2.93)$ & $1.52(0.63-3.66)$ & $0.85(0.25-2.76)$ \\
\hline Multivariate $\mathrm{HR}^{\mathrm{a}}$ & $1.09(0.59-2.03)$ & $1.34(0.42-4.24)$ & $0.99(0.31-3.09)$ & $0.48(0.08-2.76)$ \\
\hline
\end{tabular}

Abbreviations: CI, confidence interval; CIMP, CpG island methylator phenotype, according to an eight-gene panel; HR, hazard ratio, determined by Cox proportional hazard models; MSI, microsatellite instability; MSS, microsatellite stable.

${ }^{a}$ Adjusted for sex, age, tumor site, tumor stage, and adjuvant chemotherapy.

${ }^{\mathrm{b}}$ CIMP-negative, 0 genes hypermethylated; CIMP-low, 1-5 genes hypermethylated; CIMP-high, 6-8 genes hypermethylated.

our findings justify the use of tumor infiltrating $\mathrm{T}$ cells as a prognostic marker in stage II colorectal cancer.

The administration of radiotherapy reduces the density of $\mathrm{T}$ cells in and around a rectal cancer, ${ }^{52}$ which might complicate the relationship between Tcell infiltration and patient prognosis. In this study, however, the longer cancer-specific survival in patients with a higher degree of T-cell infiltration was consistent in preoperatively radiated and nonradiated subgroups. The degree of T-cell infiltration may thus also be a useful predictive marker in the important subgroup of rectal cancer patients who receive $5 \times 5$ Gy preoperative radiotherapy.

A majority of previous prognostic studies of lymphocytes are based on routine hematoxylin and eosin stained tissue sections, and few other large studies have investigated the potential use of CD3 as a prognostic marker in colorectal cancer. ${ }^{33,41,42,58}$ Immunohistochemical staining of CD3 marks all $\mathrm{T}$ cells, and we could therefore not consider potential effects from different T-cell subtypes, which can be used in combination to refine the prognostic power of individual measurements. However, immunohistochemical staining of CD3 alone has been shown to perform very well in the prediction of colorectal cancer patient survival. ${ }^{58}$ T-cell infiltration is not homogeneous in colorectal cancer, and attention has therefore also been focused on the predictive values of T cells in different tumor compartments. ${ }^{32,33,37,42-47}$ In this study, the separate measurements of T-cell infiltration in the tumor front, center, and intraepithelial compartment were closely correlated and were all positively associated with cancer-specific survival. Two previous studies found that a high total lymphocyte score, similar to that used in this study, more accurately predicted cancer-specific survival compared with any single score separately. ${ }^{32,58}$

The main strength of this study was the large patient group, which was well characterized with respect to clinicopathological factors. A number of potential confounders, including sex, age at diagnosis, tumor site, tumor stage, adjuvant chemotherapy, CIMP, and MSI screening status were taken into consideration. The use of a full tissue section from each tumor avoided sampling errors, which may be a concern in studies using tissue microarrays. We also used a validated eight-gene CIMP panel $^{50,51}$ and quantitative real-time PCR (MethyLight) methodology, which minimizes the detection of the biologically less relevant lower degrees of 
a

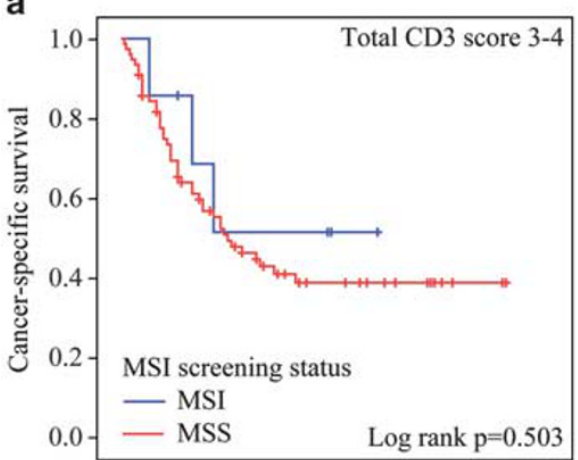

b

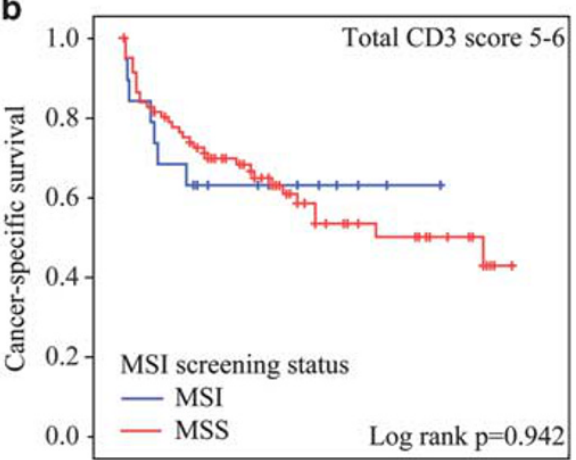

C

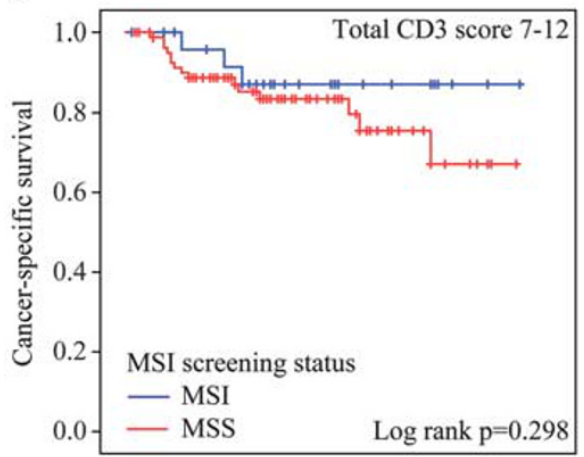

d

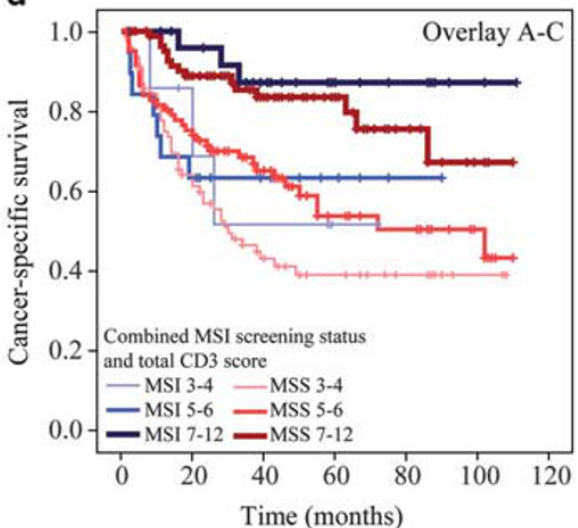

e
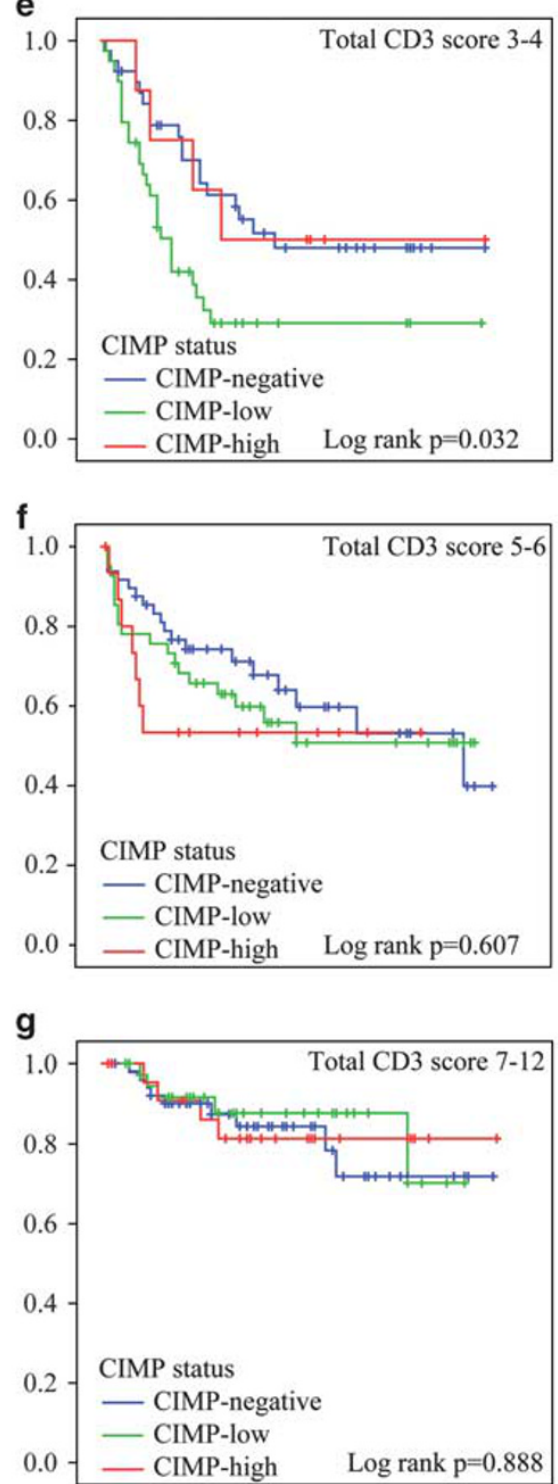

h

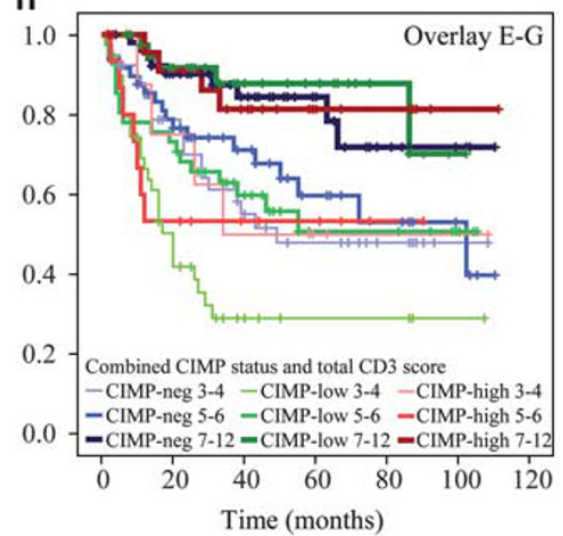

Figure 3 Cancer-specific survival in colorectal cancer patients according to (a-d) MSI screening status and (e-g) CIMP status in patients with low (a and e), intermediate (b and $\mathbf{f}$ ), and high (c and $\mathbf{g}$ ) total CD3 score. For comparison, $\mathbf{a}-\mathbf{c}$ and $\mathbf{e}-\mathbf{g}$ are combined in $\mathbf{d}$ and $\mathbf{h}$ (overlay), respectively. 
hypermethylation. ${ }^{59}$ MSI screening status was determined by immunohistochemistry for DNA mismatch repair deficiency, which has been reported to have very high sensitivity and specificity for the detection of MSI-high, ${ }^{60-62}$ but does not allow for the distinction of MSI-low. ${ }^{63}$

Despite the sample size of 446 colorectal cancer patients with immunohistochemical and survival data, some analyses, in particular for the small subgroups of MSI and CIMP-high, were limited by low power. Although we did not take into consideration the potential effects of different treatment regimes when adjusting for adjuvant chemotherapy in the multivariate analyses, the patients in this study were diagnosed during a time when treatment regimes were still relatively homogenous within each tumor site and stage. Cases of hereditary nonpolyposis colorectal cancer, who are typically MSI and highly infiltrated by lymphocytes ${ }^{64}$ were not identified in this study. These cases should not exceed $5 \%$ of the colorectal cancer cases studied. ${ }^{65}$ The number of harvested nodes is another interesting confounding factor that our findings were not adjusted for. A recent study by Ogino et $a l^{32}$ found an association between lymphocyte infiltration and patient survival that was independent of the lymph node count, MSI, and CIMP.

In conclusion, our results indicate that a high total CD3 score is predictive of a longer colorectal cancer-specific survival, largely independent of potentially important factors, such as MSI, CIMP, tumor stage, and preoperative radiotherapy. There is a need of future randomized studies that include T-cell infiltration in the treatment decision protocols for adjuvant chemotherapy.

\section{Acknowledgements}

We thank all participants in CRUMS. We also thank Kerstin Näslund, Department of Medical Biosciences, Umeå University, for excellent technical assistance. This study was financially supported by grants from the Swedish Cancer Society (RP), the Cancer Research Foundation in Northern Sweden (AMD, RP, MLH, JR, BVG), the Swedish Research Council (RP), the Faculty of Medicine, Umeå University, Umeå, Sweden (RP, JR), the J C Kempe Memorial Fund (AMD), and the Cutting-Edge Research Grant from the County Council of Västerbotten, Sweden (RP).

\section{Disclosure/conflict of interest}

The authors declare no conflict of interest.

\section{References}

1 Popat S, Hubner R, Houlston RS. Systematic review of microsatellite instability and colorectal cancer prognosis. J Clin Oncol 2005;23:609-618.
2 Guastadisegni C, Colafranceschi M, Ottini L, et al. Microsatellite instability as a marker of prognosis and response to therapy: a meta-analysis of colorectal cancer survival data. Eur J Cancer 2010;46:2788-2798.

3 Kane MF, Loda M, Gaida GM, et al. Methylation of the hMLH1 promoter correlates with lack of expression of hMLH1 in sporadic colon tumors and mismatch repairdefective human tumor cell lines. Cancer Res 1997;57: 808-811.

4 Hawkins N, Norrie M, Cheong K, et al. CpG island methylation in sporadic colorectal cancers and its relationship to microsatellite instability. Gastroenterology 2002;122:1376-1387.

5 Toyota M, Ahuja N, Ohe-Toyota M, et al. CpG island methylator phenotype in colorectal cancer. Proc Natl Acad Sci USA 1999;96:8681-8686.

6 Kambara T, Simms LA, Whitehall VL, et al. BRAF mutation is associated with DNA methylation in serrated polyps and cancers of the colorectum. Gut 2004;53:1137-1144.

7 Ogino S, Kawasaki T, Kirkner GJ, et al. CpG island methylator phenotype-low (CIMP-low) in colorectal cancer: possible associations with male sex and KRAS mutations. J Mol Diagn 2006;8:582-588.

8 Shen L, Toyota M, Kondo Y, et al. Integrated genetic and epigenetic analysis identifies three different subclasses of colon cancer. Proc Natl Acad Sci USA 2007;104:18654-18659.

9 Van Rijnsoever M, Elsaleh H, Joseph D, et al. CpG island methylator phenotype is an independent predictor of survival benefit from 5-fluorouracil in stage III colorectal cancer. Clin Cancer Res 2003;9:2898-2903.

10 Shen L, Catalano PJ, Benson III AB, et al. Association between DNA methylation and shortened survival in patients with advanced colorectal cancer treated with 5-fluorouracil based chemotherapy. Clin Cancer Res 2007;13:6093-6098.

11 Barault L, Charon-Barra C, Jooste V, et al. Hypermethylator phenotype in sporadic colon cancer: study on a population-based series of 582 cases. Cancer Res 2008;68:8541-8546.

12 Dahlin AM, Palmqvist R, Henriksson ML, et al. The role of the $\mathrm{CpG}$ island methylator phenotype in colorectal cancer prognosis depends on microsatellite instability screening status. Clin Cancer Res 2010; 16:1845-1855.

13 van Rijnsoever M, Grieu F, Elsaleh $\mathrm{H}$, et al. Characterisation of colorectal cancers showing hypermethylation at multiple CpG islands. Gut 2002;51:797-802.

14 Samowitz WS, Sweeney C, Herrick J, et al. Poor survival associated with the BRAF V600E mutation in microsatellite-stable colon cancers. Cancer Res 2005;65:6063-6069.

15 Ogino S, Nosho K, Kirkner GJ, et al. CpG island methylator phenotype, microsatellite instability, BRAF mutation and clinical outcome in colon cancer. Gut 2009;58:90-96.

16 Sanchez JA, Krumroy L, Plummer S, et al. Genetic and epigenetic classifications define clinical phenotypes and determine patient outcomes in colorectal cancer. Br J Surg 2009;96:1196-1204.

17 Kim JH, Shin SH, Kwon HJ, et al. Prognostic implications of $\mathrm{CpG}$ island hypermethylator phenotype in colorectal cancers. Virchows Arch 2009;455:485-494.

18 Samowitz WS, Curtin K, Wolff RK, et al. Microsatellite instability and survival in rectal cancer. Cancer Causes Control 2009;20:1763-1768. 
19 Maccarty WC. Longevity in cancer: a study of 293 cases. Ann Surg 1922;76:9-12.

20 Spratt Jr JS, Spjut HJ. Prevalence and prognosis of individual clinical and pathologic variables associated with colorectal carcinoma. Cancer 1967;20: 1976-1985.

21 Murray D, Hreno A, Dutton J, et al. Prognosis in colon cancer: a pathologic reassessment. Arch Surg 1975; 110:908-913.

22 Zamcheck N, Doos WG, Prudente R, et al. Prognostic factors in colon carcinoma: correlation of serum carcinoembryonic antigen level and tumor histopathology. Hum Pathol 1975;6:31-45.

23 Zhou XG, Yu BM, Shen YX. Surgical treatment and late results in 1226 cases of colorectal cancer. Dis Colon Rectum 1983;26:250-256.

24 Jass JR, Atkin WS, Cuzick J, et al. The grading of rectal cancer: historical perspectives and a multivariate analysis of 447 cases. Histopathology 1986;10: 437-459.

25 Halvorsen TB, Seim E. Association between invasiveness, inflammatory reaction, desmoplasia and survival in colorectal cancer. J Clin Pathol 1989;42:162-166.

26 Nielsen HJ, Hansen U, Christensen IJ, et al. Independent prognostic value of eosinophil and mast cell infiltration in colorectal cancer tissue. J Pathol 1999; 189:487-495.

27 Nagtegaal ID, Marijnen CA, Kranenbarg EK, et al. Local and distant recurrences in rectal cancer patients are predicted by the nonspecific immune response; specific immune response has only a systemic effect-a histopathological and immunohistochemical study. BMC Cancer 2001;1:7.

28 Ueno H, Murphy J, Jass JR, et al. Tumour 'budding' as an index to estimate the potential of aggressiveness in rectal cancer. Histopathology 2002;40:127-132.

29 Pages F, Berger A, Camus M, et al. Effector memory T cells, early metastasis, and survival in colorectal cancer. N Engl J Med 2005;353:2654-2666.

30 Baker K, Zlobec I, Tornillo L, et al. Differential significance of tumour infiltrating lymphocytes in sporadic mismatch repair deficient versus proficient colorectal cancers: a potential role for dysregulation of the transforming growth factor-beta pathway. Eur J Cancer 2007;43:624-631.

31 Morris M, Platell C, Iacopetta B. Tumor-infiltrating lymphocytes and perforation in colon cancer predict positive response to 5-fluorouracil chemotherapy. Clin Cancer Res 2008;14:1413-1417.

32 Ogino S, Nosho K, Irahara N, et al. Lymphocytic reaction to colorectal cancer is associated with longer survival, independent of lymph node count, microsatellite instability, and CpG island methylator phenotype. Clin Cancer Res 2009;15:6412-6420.

33 Simpson JA, Al-Attar A, Watson NF, et al. Intratumoral $\mathrm{T}$ cell infiltration, MHC class I and STAT1 as biomarkers of good prognosis in colorectal cancer. Gut 2010;59:926-933.

34 Call ME, Wucherpfennig KW. The T cell receptor: critical role of the membrane environment in receptor assembly and function. Annu Rev Immunol 2005; 23:101-125.

35 Michael-Robinson JM, Biemer-Huttmann A, Purdie $\mathrm{DM}$, et al. Tumour infiltrating lymphocytes and apoptosis are independent features in colorectal cancer stratified according to microsatellite instability status. Gut 2001;48:360-366.
36 Guidoboni M, Gafa R, Viel A, et al. Microsatellite instability and high content of activated cytotoxic lymphocytes identify colon cancer patients with a favorable prognosis. Am J Pathol 2001;159: 297-304.

37 Menon AG, Janssen-van Rhijn CM, Morreau H, et al. Immune system and prognosis in colorectal cancer: a detailed immunohistochemical analysis. Lab Invest 2004;84:493-501.

38 Ogino S, Odze RD, Kawasaki T, et al. Correlation of pathologic features with $\mathrm{CpG}$ island methylator phenotype (CIMP) by quantitative DNA methylation analysis in colorectal carcinoma. Am J Surg Pathol 2006;30:1175-1183.

39 Chiba T, Ohtani H, Mizoi T, et al. Intraepithelial CD8+ T-cell-count becomes a prognostic factor after a longer follow-up period in human colorectal carcinoma: possible association with suppression of micrometastasis. Br J Cancer 2004;91:1711-1717.

40 Salama P, Phillips M, Grieu F, et al. Tumor-infiltrating FOXP3+ T regulatory cells show strong prognostic significance in colorectal cancer. J Clin Oncol 2009; 27:186-192.

41 Laghi L, Bianchi P, Miranda E, et al. CD3+ cells at the invasive margin of deeply invading (pT3-T4) colorectal cancer and risk of post-surgical metastasis: a longitudinal study. Lancet Oncol 2009;10:877-884.

42 Nosho K, Baba Y, Tanaka N, et al. Tumour-infiltrating T-cell subsets, molecular changes in colorectal cancer and prognosis: cohort study and literature review. J Pathol 2010;222:350-366.

43 Svennevig JL, Lunde OC, Holter J, et al. Lymphoid infiltration and prognosis in colorectal carcinoma. Br J Cancer 1984;49:375-377.

44 Naito Y, Saito K, Shiiba K, et al. CD8+ T cells infiltrated within cancer cell nests as a prognostic factor in human colorectal cancer. Cancer Res 1998; 58:3491-3494.

45 Baeten CI, Castermans K, Hillen HF, et al. Proliferating endothelial cells and leukocyte infiltration as prognostic markers in colorectal cancer. Clin Gastroenterol Hepatol 2006;4:1351-1357.

46 Deschoolmeester V, Baay M, Van Marck E, et al. Tumor infiltrating lymphocytes: an intriguing player in the survival of colorectal cancer patients. BMC Immunol 2010;11:19.

47 Lee WS, Park S, Lee WY, et al. Clinical impact of tumor-infiltrating lymphocytes for survival in stage II colon cancer. Cancer 2010;116:5188-5199.

48 Benlloch S, Paya A, Alenda C, et al. Detection of BRAF V600E mutation in colorectal cancer: comparison of automatic sequencing and real-time chemistry methodology. J Mol Diagn 2006;8:540-543.

49 Van Guelpen B, Dahlin AM, Hultdin J, et al. One-carbon metabolism and $\mathrm{CpG}$ island methylator phenotype status in incident colorectal cancer: a nested case-referent study. Cancer Causes Control 2010;21:557-566.

50 Weisenberger DJ, Siegmund KD, Campan M, et al. CpG island methylator phenotype underlies sporadic microsatellite instability and is tightly associated with BRAF mutation in colorectal cancer. Nat Genet 2006;38:787-793.

51 Ogino S, Kawasaki T, Kirkner GJ, et al. Evaluation of markers for $\mathrm{CpG}$ island methylator phenotype (CIMP) in colorectal cancer by a large population-based sample. J Mol Diagn 2007;9:305-314. 
52 Nagtegaal ID, Marijnen CA, Kranenbarg EK, et al. Short-term preoperative radiotherapy interferes with the determination of pathological parameters in rectal cancer. J Pathol 2002;197:20-27.

53 Prall F, Duhrkop T, Weirich V, et al. Prognostic role of CD8+ tumor-infiltrating lymphocytes in stage III colorectal cancer with and without microsatellite instability. Hum Pathol 2004;35:808-816.

54 Sinicrope FA, Rego RL, Ansell SM, et al. Intraepithelial effector $(\mathrm{CD} 3+) /$ regulatory (FoxP3+) T-cell ratio predicts a clinical outcome of human colon carcinoma. Gastroenterology 2009;137:1270-1279.

55 Chang EY, Dorsey PB, Frankhouse J, et al. Combination of microsatellite instability and lymphocytic infiltrate as a prognostic indicator in colon cancer. Arch Surg 2009;144:511-515.

56 Jass JR. Classification of colorectal cancer based on correlation of clinical, morphological and molecular features. Histopathology 2007;50:113-130.

57 Ogino S, Goel A. Molecular classification and correlates in colorectal cancer. J Mol Diagn 2008;10: 13-27.

58 Galon J, Costes A, Sanchez-Cabo F, et al. Type, density, and location of immune cells within human colorectal tumors predict clinical outcome. Science 2006;313: 1960-1964.

59 Ogino S, Kawasaki T, Brahmandam M, et al. Precision and performance characteristics of bisulfite conversion and real-time PCR (MethyLight) for quantitative DNA methylation analysis. J Mol Diagn 2006;8:209-217.

60 Ruszkiewicz A, Bennett G, Moore J, et al. Correlation of mismatch repair genes immunohistochemistry and microsatellite instability status in HNPCC-associated tumours. Pathology 2002;34:541-547.

61 Lindor NM, Burgart LJ, Leontovich O, et al. Immunohistochemistry versus microsatellite instability testing in phenotyping colorectal tumors. J Clin Oncol 2002; 20:1043-1048.

62 Bertagnolli MM, Niedzwiecki D, Compton CC, et al. Microsatellite instability predicts improved response to adjuvant therapy with irinotecan, fluorouracil, and leucovorin in stage III colon cancer: Cancer and Leukemia Group B Protocol 89803. J Clin Oncol 2009; 27:1814-1821.

63 Boland CR, Thibodeau SN, Hamilton SR, et al. A National Cancer Institute Workshop on Microsatellite Instability for cancer detection and familial predisposition: development of international criteria for the determination of microsatellite instability in colorectal cancer. Cancer Res 1998;58:5248-5257.

64 Jass JR, Walsh MD, Barker M, et al. Distinction between familial and sporadic forms of colorectal cancer showing DNA microsatellite instability. Eur J Cancer 2002;38:858-866.

65 de la Chapelle A. Genetic predisposition to colorectal cancer. Nat Rev Cancer 2004;4:769-780.

Supplementary Information accompanies the paper on Modern Pathology website (http://www.nature.com/ modpathol) 